Article

\title{
Emergency Department as the Entry Point to Inpatient Care: A Nationwide, Population-Based Study in South Korea, 2016-2018
}

\author{
June-sung Kim ${ }^{1}$, Dong Woo Seo ${ }^{1}$, Youn-Jung Kim ${ }^{1}$, Seok In Hong ${ }^{1} \mathbb{D}$, Hyunggoo Kang ${ }^{2} \mathbb{D}, \mathrm{Su} \mathrm{Jin}_{\mathrm{Kim}}{ }^{3}$, \\ Kap Su Han ${ }^{3} \mathbb{D}$, Sung Woo Lee ${ }^{3} \mathbb{D}$, Sungwoo Moon ${ }^{4}$ and Won Young Kim ${ }^{1, * \mathbb{D}}$
}

1 Department of Emergency Medicine, Asan Medical Center, University of Ulsan College of Medicine, Seoul 05505, Korea; jsmeet09@gmail.com (J.-s.K.); leiseo@gmail.com (D.W.S.); yjkim.em@gmail.com (Y.-J.K.); finefigs@gmail.com (S.I.H.)

2 Department of Emergency Medicine, Hanyang University College of Medicine, Seoul 04763, Korea; emer0905@gmail.com

3 Department of Emergency Medicine, Korea University College of Medicine, Seoul 02841, Korea; icarusksj@gmail.com (S.J.K.); hanks96@hanmail.net (K.S.H.); kuedlee@korea.ac.kr (S.W.L.)

4 Department of Emergency Medicine, Korea University Ansan Hospital, Ansan 15355, Korea; yg9912@korea.ac.kr

* Correspondence: wonpia73@naver.com; Tel.: +82-2-3010-3350

check for updates

Citation: Kim, J.-s.; Seo, D.W.; Kim, Y.-J.; Hong, S.I.; Kang, H.; Kim, S.J.; Han, K.S.; Lee, S.W.; Moon, S.; Kim, W.Y. Emergency Department as the Entry Point to Inpatient Care: A Nationwide, Population-Based Study in South Korea, 2016-2018. J. Clin. Med. 2021, 10, 1747. https://doi.org/ $10.3390 /$ jcm 10081747

Academic Editor: John G. Kellett

Received: 3 March 2021

Accepted: 14 April 2021

Published: 17 April 2021

Publisher's Note: MDPI stays neutral with regard to jurisdictional claims in published maps and institutional affiliations.

Copyright: (c) 2021 by the authors. Licensee MDPI, Basel, Switzerland. This article is an open access article distributed under the terms and conditions of the Creative Commons Attribution (CC BY) license (https:// creativecommons.org/licenses/by/ $4.0 /)$.

\begin{abstract}
Background: The emergency department provides lifesaving treatment and has become an entry point to hospital admission. The purpose of our study was to describe the characteristics and outcomes of patients who were admitted through the emergency department to the intensive care unit or general ward. (2) Methods: We performed a retrospective, cross-sectional, descriptive analysis using the National Emergency Department Information System, analyzing patient data including disease category, diagnosis, and mortality from 1 January 2016, to 31 December 2018. (3) Results: During the study period, about $13.6 \%$ were admitted through the emergency department. Of these, the overall in-hospital mortality was $4.6 \%$. The frequent disease class for the intensive care unit admissions was the cardiovascular system, and the classes for the general ward admissions were as follows: injury and toxicology, digestive system, and respiratory system. Cardiovascular system-related emergencies were the predominant cause of death among patients admitted to the intensive care unit; however, oncologic complications were the leading cause of death in the general ward. (4) Conclusions: Emergency departments are incrementally utilized as the entry point for hospital admission. Health care providers need to understand emergency department admission epidemiology and prepare for managing patients with certain common diagnoses.
\end{abstract}

Keywords: hospital admission; epidemiology; hospital utilization; emergency department

\section{Introduction}

Emergency departments (EDs) have a crucial role in the health care system, acting as hospital admission gatekeepers and a place for the provision of lifesaving treatment. Recent studies have proven that immediate interventions and admission through an ED for various diseases, such as ST-segment elevation myocardial infarction, acute ischemic stroke, and geriatric trauma, could improve outcomes [1-3]. The utility of EDs has been increasing and has outpaced the growth of the general population. This has been caused primarily by an increase in the proportion of aging patients with greater rates of chronic diseases [4,5]. Admissions through an ED have also increased simultaneously [6]. Between 2003 and 2009 in the United States of America (USA), hospital admissions originating in the ED increased by $17 \%$, whereas admissions from physicians' offices and clinics decreased by 10\% [7]. Furthermore, another study announced that $70 \%$ of hospital admissions were processed through the ED, and there was a linear association between age and the ED admission in 
the USA [8]. The characteristics of admissions through the ED greatly differ from those of regularly scheduled admissions. Patients requiring emergency admission were typically older, had more comorbidities, and had severe acute illnesses [9]. Moreover, there were potential differences in emergency admitted patients between the general ward (GW) and intensive care unit (ICU) $[10,11]$. Assessing the epidemiology of patients admitted through an ED is essential to prepare and manage hospital bed resource; however, data on disease classification, specific diagnosis, and mortality in patients admitted from the ED to the hospital are limited. Kwak et al. conducted a retrospective study and described the nation-wide ED utilization pattern by children in Korea [12]. Chen et al. compared the epidemiological characteristics and disease spectrum of patients of two EDs in China [13]. However, these studies did not provide specific diagnoses, classifications, and mortality for both the ICU and GW [12,13].

The primary purpose of this study was to describe common disease classifications and specific diagnoses in patients admitted to the hospital from the ED between 2016 and 2018. We also examined the frequent specific diagnoses in non-survival patients to provide insights for preparing future medical resources.

\section{Materials and Methods}

\subsection{Study Design}

This retrospective, cross-sectional, descriptive, nationwide study was conducted using the National Emergency Department Information System (NEDIS) between 1 January 2016, and 31 December 2018. NEDIS was started in 2003 by the Ministry of Health and Welfare and is managed by the National Emergency Medical Center of Korea. NEDIS covers all clinical and administrative data on patients who visit EDs throughout the country to maintain ED quality and enhance the emergency medical service system [14]. It is regarded as a reliable source of ED data due to the fact that $>98 \%$ of EDs participate in the system and annual governmental review of the data. This study was approved by the Institutional Review Board of the study facility, and informed consent was waived because of the anonymous nature of the data.

\subsection{Study Setting and Population}

According to the Korean Emergency Medical Care Act, there are three categories of EDs, ranging from large to small regarding the size and role of EDs, i.e., regional emergency centers, local emergency centers, and local emergency institutes. The NEDIS has a variable to differentiate the hospitals according to the levels. We included all admitted patients through EDs of both regional emergency centers and local emergency centers. Patients were excluded if they had visited local emergency institutes because the characteristics of patient population and disease spectrum were totally different from others. Most local emergency institutes in Korea have no ICUs and find it hard to manage patients with critical illnesses. In addition, we excluded patients who were discharged, died, transferred to other hospitals in the ED, or had missing outcome data, such as lost to follow-up. Available variables were extracted, such as demographics, insurance status, route of arrival (direct from the scene or home, transfer from other outpatient clinic or hospital), causes of ED visits (medical or trauma), acuity at the initial triage, and location of admission. According to the Korean Triage and Acuity Scale (KTAS), acuity at the initial triage was rated between 1 and 5, with level 1 indicating the most severely ill patients $[15,16]$. Length of stay, in line with the previous study, was defined as the interval (in minutes) between patient arrival at the ED and subsequent departure [17].

\subsection{Measures}

We compared the number and rate of admissions by location (i.e., ICU and GW) and collected clinical outcomes on the admitted patients, including discharge, death, and transfer. Others $(0.7 \%)$ included all unclassified cases discharged without adequate recommendations and patients who ran away. We used the final diagnosis on admission 
according to the Korean Standard Classification of Disease and Cause of Death (KCD) codes [18]. KCD codes are managed by Statistics Korea, a central organization for statistics under the Ministry of Strategy and Finance, and identical to the International Classification of Disease 10. Furthermore, the diseases and causes of death were classified based on Statistics Korea.

\subsection{Data Analysis}

All statistical analyses were performed with R statistics software, version 3.5.0 (R Foundation for Statistical Computing, Vienna, Austria). Continuous parameters were presented as means and standard deviations (S) and compared using the Student's t-test or the Mann-Whitney $U$ test. Categorical parameters were expressed as a number and percentage and compared with chi-square tests. $p$ values of $<0.05$ were considered to be statistically significant.

\section{Results}

A total of $27,483,303$ patients visited EDs throughout Korea (9,127,979 vs. 9,089,055 vs. $9,266,269,2016,2017,2018$, respectively) during the study period, of these, $21,844,366$ (83.7\%) were discharged, $145,250(0.6 \%)$ died in the EDs, and 467,592 (1.8\%) were transferred to other hospitals (Figure 1). Of the 3,539,945 (13.6\%) ED admissions (599,434 (92.3\%) for ICU and 2,950,511 (11.3\%) for GW), 3,004,984 (86.1\%) resulted in discharge, 162,065 (4.6\%) died during hospital stay, and 295,706 (8.5\%) were transferred to other hospitals after discharge. The total admission number and rates continuously increased from 1,144,407 (12.5\%) in 2016 to $1,215,171(13.1 \%)$ in 2018. Furthermore, the absolute number of admissions to the GW continuously increased from $2016(n=943,737)$ to $2018(n=1,021,534)$ (Figure 2). Meanwhile, the number of admissions to the ICU decreased from $2016(n=200,607)$ to 2018 $(n=193,637)$.

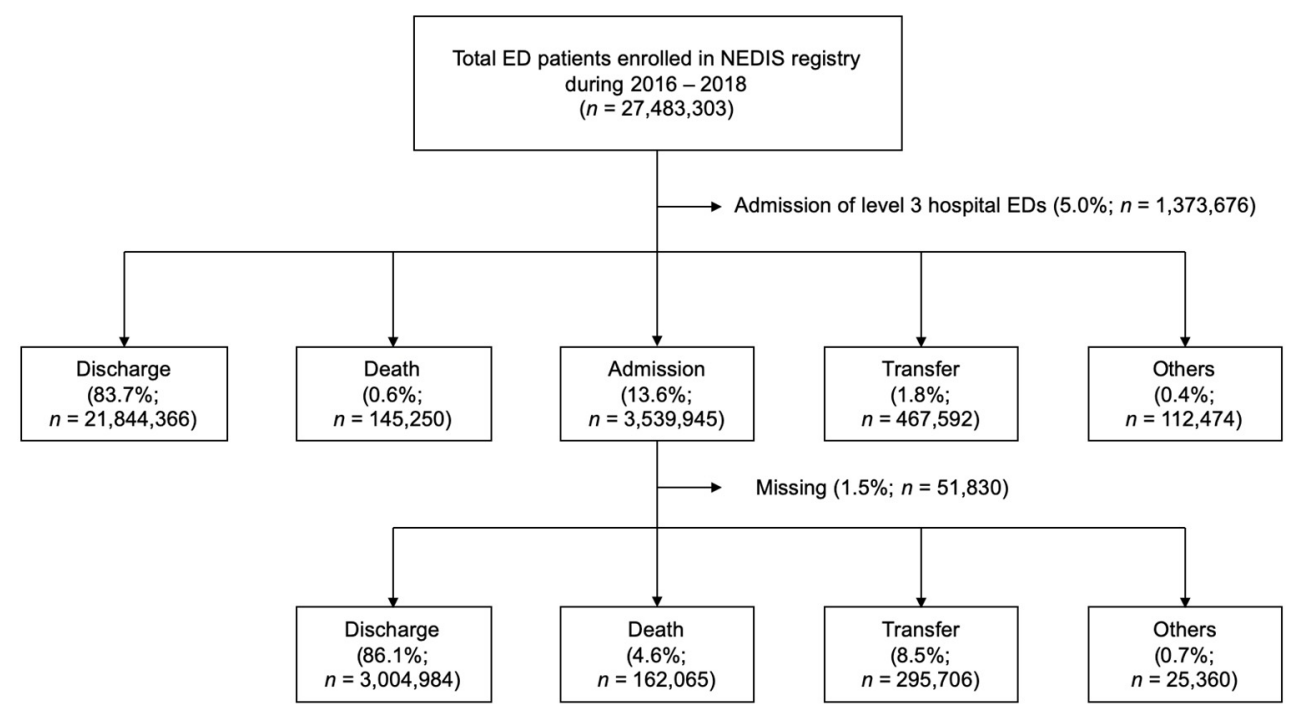

Figure 1. Study flowchart. ED, emergency department; NEDIS, National Emergency Department Information System.

\subsection{Baseline Characteristics of the Study Population}

Table 1 shows the baseline characteristics of patients admitted through the ED according to the admission location. Male sex was predominant with a mean age of 53.4 years old. Direct visits (61.1 for ICU vs. $68.9 \%$ for GW) and transfers from outpatient departments ( 2.5 vs. $5.2 \%$ ) were frequent in the GW group, and transfers from other hospitals (36.4 vs. $25.9 \%$ ) were common in the ICU group. Medical problems were prevalent in both groups ( 80.6 vs. $82.7 \%$ ), and mean ED length of stay was significantly shorter in the ICU group 
than in the GW group (353.2 vs. $455.0 \mathrm{~min}$ ). KTAS 1 and 2, called severe illness, were more common in the ICU group (10.0 vs. $0.8 \%$ for KTAS 1, 37.5 vs. $10.5 \%$ for KTAS 2 ).

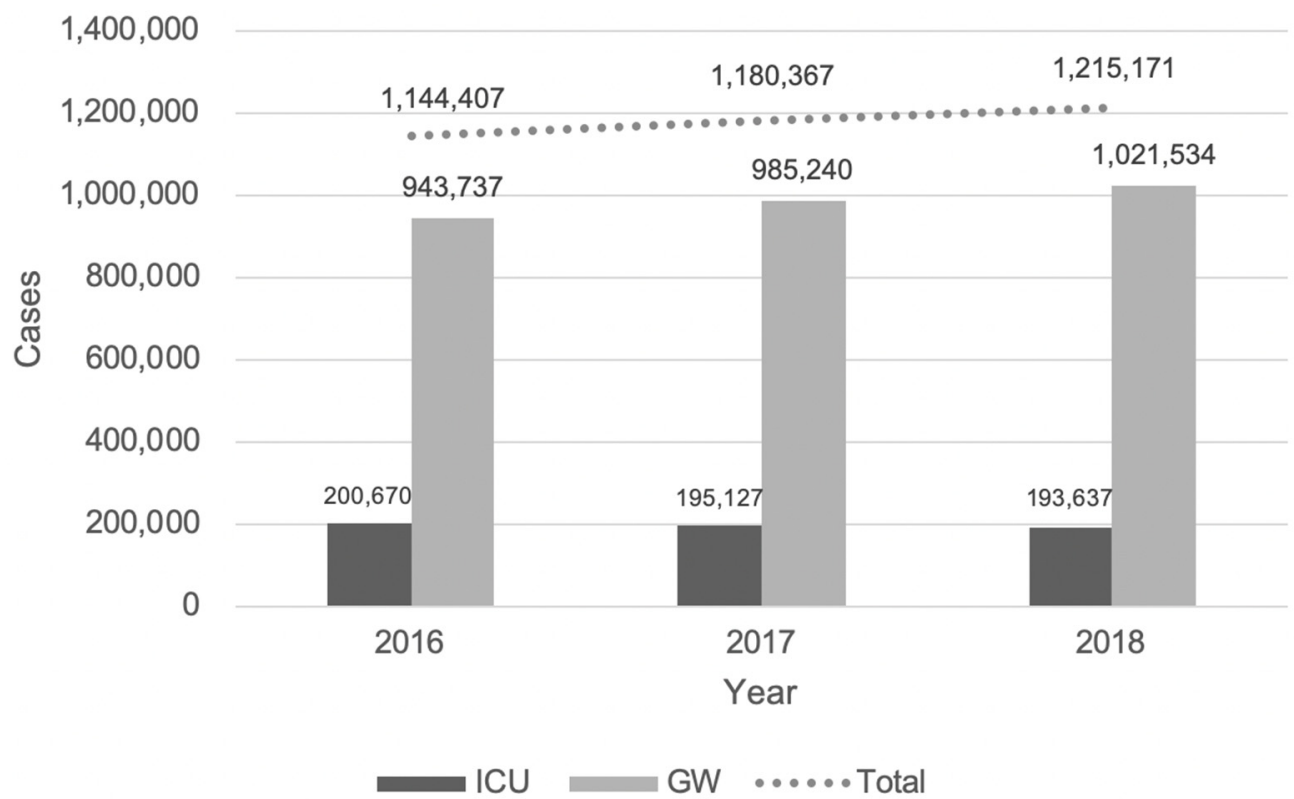

Figure 2. Trends of the total admission through the emergency department during the study period. ED, emergency department; GW, general ward; ICU, intensive care unit.

Table 1. Baseline characteristics of the study population.

\begin{tabular}{|c|c|c|c|c|}
\hline Variable & $\begin{array}{c}\text { Total } \\
(n=3,539,945)\end{array}$ & $\begin{array}{c}\text { ICU } \\
(n=589,434)\end{array}$ & $\begin{array}{c}\mathrm{GW} \\
(n=2,950,511)\end{array}$ & $p$ \\
\hline \multicolumn{5}{|l|}{ Gender } \\
\hline Male $(n, \%)$ & $1,908,254(53.9)$ & $350,475(59.5)$ & $1,557,779(52.8)$ & $<0.01$ \\
\hline Female $(n, \%)$ & $1,631,691(46.1)$ & $238,959(40.5)$ & $1,392,732(47.2)$ & $<0.01$ \\
\hline Age (year) & $53.4 \pm 25.7$ & $62.5 \pm 20.2$ & $51.6 \pm 26.3$ & $<0.01$ \\
\hline$<18(n, \%)$ & $491,239(13.9)$ & $25,916(4.4)$ & $465,323(15.8)$ & \\
\hline $18-44(n, \%)$ & $638,695(18.0)$ & $71,253(12.1)$ & $567,442(19.2)$ & \\
\hline $45-64(n, \%)$ & $1,013,495(28.6)$ & $191,046(32.4)$ & $2,950,511(27.9)$ & \\
\hline$\geq 65(n, \%)$ & $1,396,515(39.5)$ & $301,218(51.1)$ & $1,095,297(37.1)$ & \\
\hline National insurance $(n, \%)$ & $3,038,589(85.8)$ & $484,277(82.2)$ & $2,554,312(86.6)$ & $<0.01$ \\
\hline Route of arrival & & & & $<0.01$ \\
\hline Directly visit $(n, \%)$ & $2,391,715(67.6)$ & $359,984(61.1)$ & $2,031,731(68.9)$ & \\
\hline Referred from OPD $(n, \%)$ & $169,338(4.8)$ & $14,608(2.5)$ & $154,730(5.2)$ & \\
\hline From other hospitals $(n, \%)$ & $977,557(27.6)$ & $214,501(36.4)$ & $763,056(25.9)$ & \\
\hline Others $(n, \%)$ & $1076(0.0)$ & $244(0.0)$ & $832(0.0)$ & \\
\hline Unknown & $259(0.0)$ & $97(0.0)$ & $162(0.0)$ & \\
\hline Disease type & & & & $<0.01$ \\
\hline Medical $(n, \%)$ & $2,913,685(82.3)$ & $474,860(80.6)$ & $2,438,825(82.7)$ & \\
\hline Trauma $(n, \%)$ & $606,336(17.1)$ & $97,452(16.5)$ & $508,884(17.2)$ & \\
\hline Unknown $(n, \%)$ & $19,924(0.6)$ & $17,122(2.9)$ & $2802(0.1)$ & \\
\hline EDLOS (min) & $438.0 \pm 665.1$ & $353.2 \pm 741.4$ & $455.0 \pm 647.5$ & $<0.01$ \\
\hline Level of hospital & & & & $<0.01$ \\
\hline Regional emergency centers $(n, \%)$ & $1,293,935(36.6)$ & $252,362(42.8)$ & $1,041,573(35.3)$ & \\
\hline Local emergency centers $(n, \%)$ & $2,246,010(63.4)$ & $337,072(57.2)$ & $1,908,938(64.7)$ & \\
\hline KTAS & & & & $<0.01$ \\
\hline $1(n, \%)$ & $83,101(2.3)$ & $58,811(10.0)$ & $24,290(0.8)$ & \\
\hline $2(n, \%)$ & $530,657(15.0)$ & $221,319(37.5)$ & $309,338(10.5)$ & \\
\hline $3(n, \%)$ & $1,846,874(52.2)$ & $236,511(40.1)$ & $1,610,363$ (54.6) & \\
\hline $4(n, \%)$ & $941,739(26.6)$ & $46,837(7.9)$ & $894,902(30.3)$ & \\
\hline $5(n, \%)$ & $115,900(3.3)$ & $6429(1.1)$ & $109,471(3.7)$ & \\
\hline Missing $(n, \%)$ & $21,674(0.6)$ & $19,527(3.3)$ & $2147(0.1)$ & \\
\hline
\end{tabular}

Data are presented as $n$ (\%) or mean with standard deviation. ICU, intensive care unit; GW, general ward; OPD, outpatient department; EDLOS, emergency department length of stay; KTAS, Korean Triage Acuity Score. 


\subsection{Frequencies of Disease Classes}

Table 2 shows the frequencies of disease classes according to admission location. Over half (59.5\%) of all cases comprised injury $(17.2 \%)$, and emergencies related to the digestive system $(15.2 \%)$, circulatory system $(13.4 \%)$, and respiratory system $(12.7 \%)$. The circulatory system (35.3\%) was the leading cause of admission in the ICU, followed by injury $(16.8 \%)$, and respiratory system $(10.2 \%)$. Injury $(17.3 \%)$ and digestive system $(16.3 \%)$ were common in the GW, and a higher proportion of patients were admitted in the GW for neoplasms $(9.1 \%)$ than in the ICU $(4.0 \%)$.

Table 2. Frequencies of disease classes according to admission type.

\begin{tabular}{|c|c|c|c|c|c|c|}
\hline \multirow{2}{*}{ Rank } & \multicolumn{2}{|c|}{ Total $(n=3,539,945)$} & \multicolumn{2}{|c|}{ ICU $(n=589,434)$} & \multicolumn{2}{|c|}{$\mathrm{GW}(n=2,950,511)$} \\
\hline & Code & Frequency (\%) & Code & Frequency (\%) & Code & Frequency (\%) \\
\hline 1 & Injury & $608,555(17.2)$ & Circulatory system & $207,850(35.3)$ & Injury & $509,450(17.3)$ \\
\hline 2 & Digestive system & $539,058(15.2)$ & Injury & $99,105(16.8)$ & Digestive system & $481,367(16.3)$ \\
\hline 3 & Circulatory system & $472,996(13.4)$ & Respiratory system & $59,857(10.2)$ & Respiratory system & $389,908(13.2)$ \\
\hline 4 & Respiratory system & $449,765(12.7)$ & Digestive system & $57,691(9.8)$ & Neoplasms & $268,486(9.1)$ \\
\hline 5 & Neoplasms & $291,911(8.2)$ & Not classified & $33,385(5.7)$ & Circulatory system & $265,146(9.0)$ \\
\hline 6 & Genitourinary system & $246,785(7.0)$ & Genitourinary system & $27,721(4.7)$ & Infectious disease & $221,594(7.5)$ \\
\hline 7 & Infectious disease & $243,932(6.9)$ & Neoplasms & $23,425(4.0)$ & Genitourinary system & $219,064(7.4)$ \\
\hline 8 & Not classified & $225,347(6.4)$ & Infectious disease & $22,338(3.8)$ & Not classified & $191,962(6.5)$ \\
\hline 9 & Nervous system & $95,396(2.7)$ & Nervous system & $17,118(2.9)$ & Skin disorders & $78,314(2.7)$ \\
\hline 10 & $\begin{array}{l}\text { Musculoskeletal } \\
\text { system }\end{array}$ & $81,880(2.3)$ & Metabolic diseases & $16,067(2.7)$ & Nervous system & $78,278(2.7)$ \\
\hline 11 & Metabolic diseases & $76,389(2.2)$ & $\begin{array}{l}\text { Contact health } \\
\text { services }\end{array}$ & $5976(1.0)$ & Metabolic diseases & $60,322(2.0)$ \\
\hline 12 & Pregnancy & $42,813(1.2)$ & Mental disorders & $5051(0.9)$ & Pregnancy & $40,064(1.4)$ \\
\hline 13 & Ear disease & $32,286(0.9)$ & $\begin{array}{l}\text { Musculoskeletal } \\
\text { system }\end{array}$ & $3566(0.6)$ & Ear disease & $31,657(1.1)$ \\
\hline 14 & Mental disorders & $31,028(0.9)$ & Pregnancy & $2749(0.5)$ & Diseases of the skin & $28,155(1.0)$ \\
\hline 15 & Skin disorders & $29,394(0.8)$ & Blood disorders & $2042(0.4)$ & Mental disorders & $25,977(0.9)$ \\
\hline 16 & Blood disorders & $25,806(0.7)$ & Perinatal disorders & $1720(0.3)$ & Blood disorders & $23,764(0.8)$ \\
\hline 17 & $\begin{array}{l}\text { Contact health } \\
\text { services }\end{array}$ & $18,692(0.5)$ & Developmental & $1503(0.3)$ & $\begin{array}{l}\text { Contact health } \\
\text { services }\end{array}$ & $16,972(0.6)$ \\
\hline 18 & Visual system disease & $11,191(0.3)$ & Skin disorders & $1239(0.2)$ & Visual system disease & $10,945(0.4)$ \\
\hline 19 & Perinatal disorders & $8375(0.2)$ & Ear disease & $629(0.1)$ & $\begin{array}{l}\text { Developmental } \\
\text { anomalies }\end{array}$ & $6355(0.2)$ \\
\hline 20 & $\begin{array}{l}\text { Developmental } \\
\text { anomalies }\end{array}$ & $7858(0.2)$ & Visual system disease & $246(0.0)$ & Perinatal disorders & $2399(0.1)$ \\
\hline 21 & External causes & $343(0.0)$ & External causes & $132(0.0)$ & External causes & $211(0.0)$ \\
\hline 22 & Special purposes & $145(0.0)$ & Special purposes & $24(0.0)$ & Special purposes & $121(0.0)$ \\
\hline
\end{tabular}

Data are presented as $n(\%)$. ICU, intensive care unit; GW, general ward.

\subsection{Common Specific Diagnoses}

Table 3 shows the common specific diagnoses of admitted patients. Pneumonia $(0.045 \%)$ was the most common cause in the total population, followed by acute appendicitis, cerebral infarct, and acute kidney injury. Hemorrhagic stroke $(0.088 \%)$ and acute myocardial infarction $(0.083 \%)$ were predominant in the ICU, and pneumonia $(0.043 \%)$ and acute appendicitis $(0.032 \%)$ were frequent in the GW.

\subsection{Causes of Death Classification}

Figure 3 shows the most common causes of death classification. Neoplasms were the leading causes of death in the total (30\%) and GW (48\%) group. Meanwhile, diseases of the circulatory system had the largest proportion of deaths (32\%), followed by respiratory system emergencies (19\%), and injury $(12 \%)$ in the ICU group.

\subsection{Causes of Death Diagnoses}

Figure 4 shows the specific KCD codes for in-hospital deaths. Pneumonia was the most frequent diagnosis in both the ICU $(n=9392,12.3 \%)$ and GW $(n=11,009,12.9 \%)$. Sepsis $(n=4601,6.1 \%)$ was second-most common, followed by hemorrhagic stroke $(n=4450$, $5.9 \%)$, and cardiac arrest $(n=3825,5.0 \%)$ in the ICU admission. Meanwhile, incidence of cancers, including lung cancer $(n=7279,8.5 \%)$ and hepatocellular carcinoma $(n=4759,5.5 \%)$, were more common than that of sepsis $(n=2279,2.6 \%)$ in patients admitted to the GW. 
Table 3. Top 20 common diagnoses of admitted patients.

\begin{tabular}{|c|c|c|c|c|c|c|}
\hline \multirow{2}{*}{ Rank } & \multicolumn{2}{|c|}{ Total $(n=3,539,945)$} & \multicolumn{2}{|c|}{ ICU $(n=589,434)$} & \multicolumn{2}{|c|}{$\mathrm{GW}(n=2,950,511)$} \\
\hline & Code & Frequency (\%) & Code & Frequency (\%) & Code & Frequency (\%) \\
\hline $\begin{array}{l}1 \\
2\end{array}$ & $\begin{array}{c}\text { Pneumonia } \\
\text { Acute appendicitis }\end{array}$ & $\begin{array}{c}158,554(4.5) \\
95,558(2.7)\end{array}$ & $\begin{array}{c}\text { Hemorrhagic stroke } \\
\text { AMI }\end{array}$ & $\begin{array}{l}51,982(8.8) \\
49,156(8.3)\end{array}$ & $\begin{array}{c}\text { Pneumonia } \\
\text { Acute appendicitis }\end{array}$ & $\begin{array}{c}127,374(4.3) \\
93,978(3.2)\end{array}$ \\
\hline 3 & Cerebral infarct & $92,835(2.6)$ & Pneumonia & $31,180(5.3)$ & Rectal cancer & $81,405(2.8)$ \\
\hline 4 & AKI & $86,441(2.4)$ & Cerebral infarct & $28,475(4.8)$ & Cerebral infarct & $69,191(2.3)$ \\
\hline 5 & $\begin{array}{l}\text { Rectal cancer } \\
\text { complications }\end{array}$ & $84,716(2.4)$ & Sepsis & $12,448(2.1)$ & AKI & $65,760(2.2)$ \\
\hline $\begin{array}{c}6 \\
7 \\
8 \\
9 \\
10 \\
11\end{array}$ & $\begin{array}{l}\text { Urinary tract infection } \\
\text { AMI } \\
\text { Seizure } \\
\text { Femur neck fracture } \\
\text { Hemorrhagic stroke } \\
\text { Enterocolitis }\end{array}$ & $\begin{array}{l}44,178(1.2) \\
43,346(1.2) \\
37,413(1.1) \\
35,461(1.0) \\
33,500(0.9) \\
28,729(0.8)\end{array}$ & $\begin{array}{c}\text { Heart failure } \\
\text { AKI } \\
\text { Ischemic heart disease } \\
\text { Cardiac arrest } \\
\text { Urinary tract infection } \\
\text { CKD }\end{array}$ & $\begin{array}{l}10,477(1.8) \\
9236(1.6) \\
8091(1.4) \\
7831(1.3) \\
6620(1.1) \\
5127(0.9)\end{array}$ & $\begin{array}{l}\text { Urinary tract infection } \\
\text { Femur neck fracture } \\
\text { Enterocolitis } \\
\text { HCC complication } \\
\text { Concussion } \\
\text { Acute cholecystitis }\end{array}$ & $\begin{array}{l}37,558(1.3) \\
34,465(1.2) \\
27,266(0.9) \\
21,195(0.7) \\
21,000(0.7) \\
20,888(0.7)\end{array}$ \\
\hline 12 & HCC complications & $24,339(0.7)$ & $\begin{array}{l}\text { Gastrointestinal } \\
\text { hemorrhage }\end{array}$ & $4890(0.8)$ & Fever, unspecified & $20,368(0.7)$ \\
\hline $\begin{array}{l}13 \\
14 \\
15\end{array}$ & $\begin{array}{l}\text { Heart failure } \\
\text { CKD } \\
\text { Concussion }\end{array}$ & $\begin{array}{l}24,051(0.7) \\
23,140(0.7) \\
22,247(0.6)\end{array}$ & $\begin{array}{l}\text { Ischemic heart disease } \\
\text { Gastric ulcer } \\
\text { Pulmonary embolism }\end{array}$ & $\begin{array}{l}4568(0.8) \\
3552(0.6) \\
3519(0.6)\end{array}$ & $\begin{array}{l}\text { Acute pancreatitis } \\
\text { Acute cholangitis } \\
\text { Neck sprain }\end{array}$ & $\begin{array}{l}18,956(0.6) \\
18,529(0.6) \\
18,403(0.6)\end{array}$ \\
\hline 16 & Acute cholecystitis & $21,880(0.6)$ & $\begin{array}{l}\text { Rectal cancer terminal } \\
\text { complication }\end{array}$ & $3311(0.6)$ & CKD & $18,013(0.6)$ \\
\hline $\begin{array}{l}17 \\
18\end{array}$ & $\begin{array}{l}\text { Fever, unspecified } \\
\text { Acute cholangitis }\end{array}$ & $\begin{array}{l}21,255(0.6) \\
20,110(0.6)\end{array}$ & $\begin{array}{l}\text { Seizure } \\
\text { HCC complication }\end{array}$ & $\begin{array}{l}3221(0.5) \\
3144(0.5)\end{array}$ & $\begin{array}{l}\text { Seizure } \\
\text { Dizziness }\end{array}$ & $\begin{array}{l}17,904(0.6) \\
16,801(0.6)\end{array}$ \\
\hline 19 & Acute pancreatitis & $19,992(0.6)$ & $\begin{array}{c}\text { Alcoholic liver } \\
\text { cirrhosis }\end{array}$ & $2563(0.4)$ & Heart failure & $16,272(0.6)$ \\
\hline 20 & Sepsis & $19,628(0.6)$ & Pulmonary edema & $2173(0.4)$ & $\begin{array}{l}\text { Lung cancer } \\
\text { complications }\end{array}$ & $15,201(0.5)$ \\
\hline
\end{tabular}

Data are presented as $n$ (\%). ICU, intensive care unit; GW, general ward; AMI, acute myocardial infarction; AKI, acute kidney injury; HCC, hepatocellular carcinoma; CKD, chronic kidney disease.

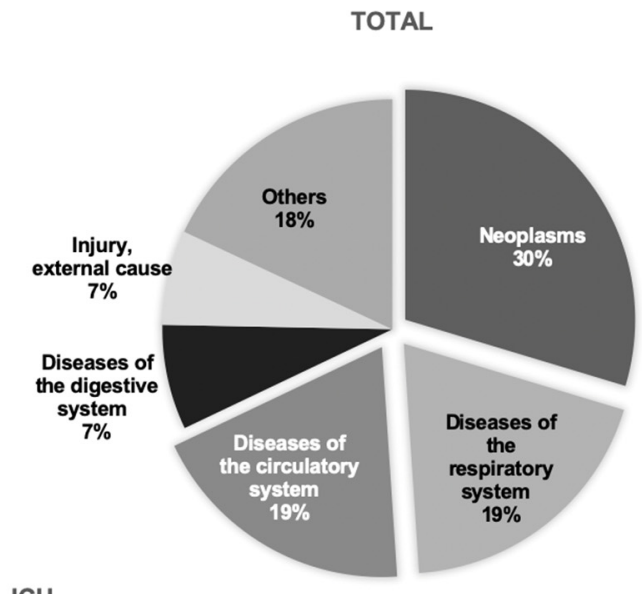

ICU

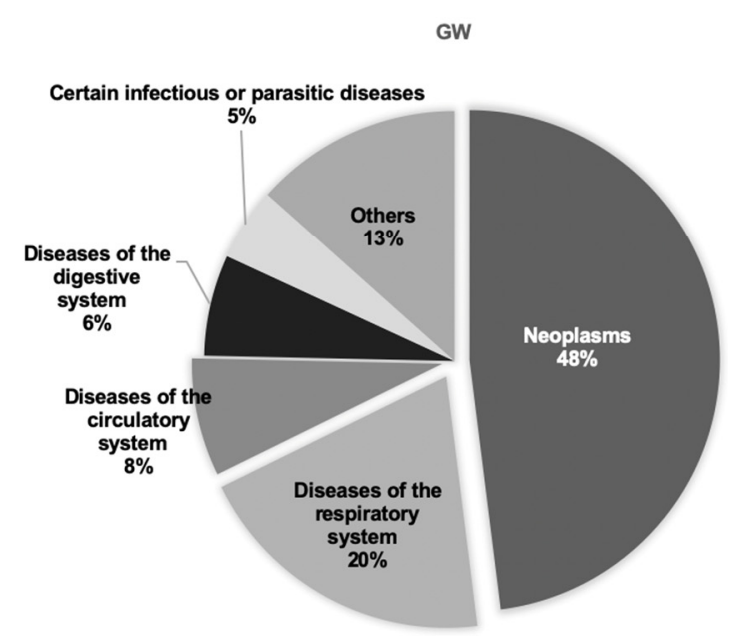

Figure 3. Top 5 disease classifications that lead to death among patients admitted through the emergency department. GW, general ward; ICU, intensive care unit. 

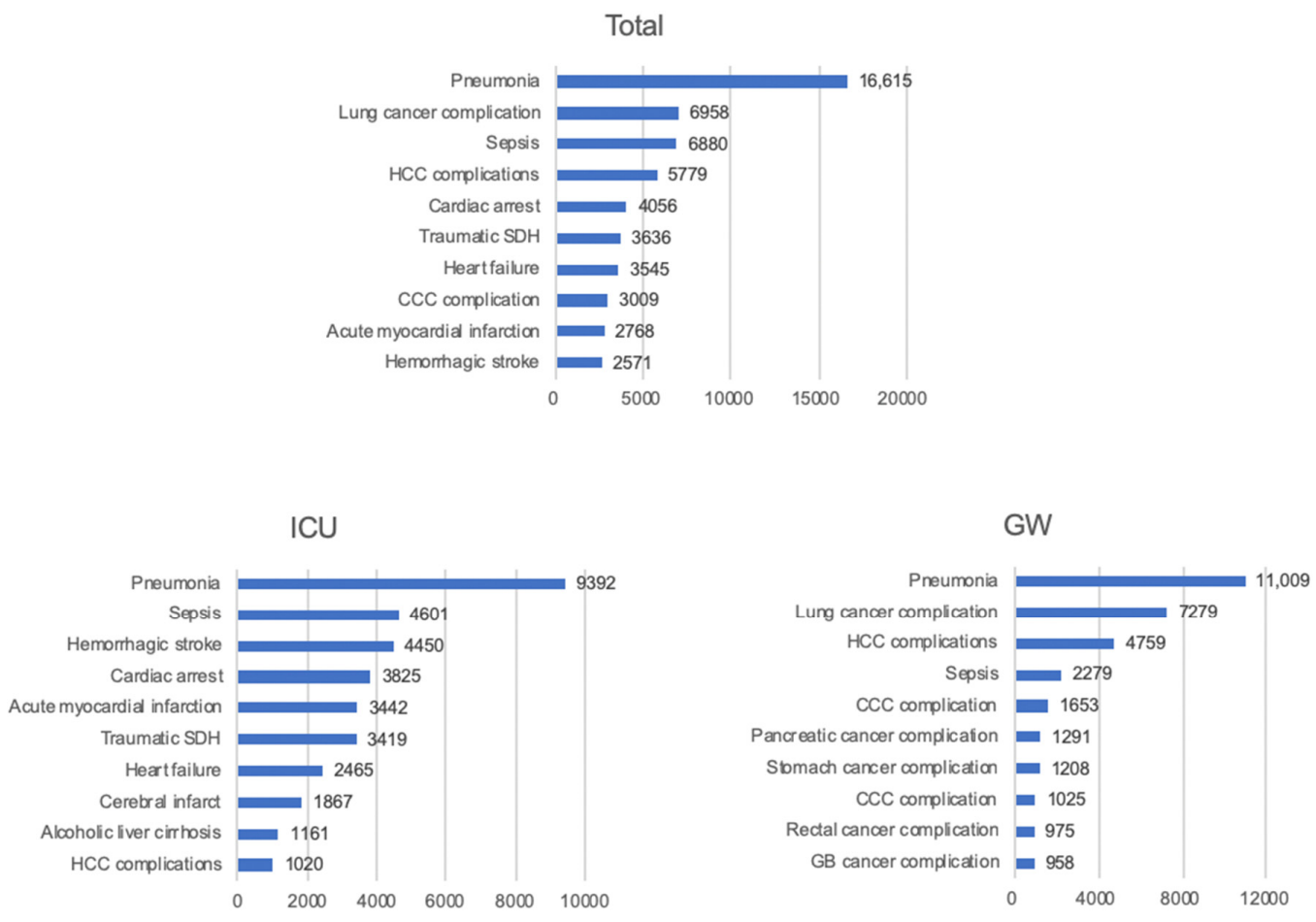

Figure 4. Top 10 diagnosed causes of death among patients admitted through the emergency department. CCC, cholangiocellular carcinoma; HCC, hepatocellular carcinoma; GB, gallbladder; GW, general ward; ICU, intensive care unit; SDH, subdural hematoma.

\section{Discussion}

Information on common causes of admission through the ED and the cause of death provide insight into a community's health care system. Our results clearly showed (1) $13.6 \%$ ( $2.3 \%$ ICU and $11.3 \% \mathrm{GW}$ ) of patients were admitted through the ED, (2) cardiovascular system-related emergencies comprised more than one-third of the total ICU admission cases, and oncologic diseases were the leading causes of GW admission, (3) around onetwentieth died during admission and pneumonia was the most common diagnosis of death for both ICU and GW, and (4) cardiovascular system-related emergencies, such as acute stroke, cardiac arrest, and myocardial infarct were the predominant cause of death in the ICU; however, oncologic complications were the leading cause of death in the GW, and digestive issues and injuries were relatively less common.

In the 2017 Emergency Department Benchmarking Alliance (EDBA) report, the performance measures survey showed that the average proportion of patients admitted to hospital from the ED was $16.9 \%$, and their length of stay was 303 min in the USA. Our study confirmed that Korea's ED admission rate is approximately $13 \%$, which increased from $12.5 \%$ in 2016 to $13.1 \%$ in 2018. This growth was primarily due to the rise in admissions to the GW. Previous epidemiologic studies of ED utilization on the detailed categorization of patients with entire emergency admission records are limited. Recent nationwide analyses in the USA reported emergency care-sensitive conditions and showed sepsis, chronic obstructive pulmonary disease, pneumonia, and heart failure were predominant [19]. In line with previous research, we found that cardiovascular, pulmonary, gastrointestinal, and oncologic issues were the leading causes of urgent admissions. Moreover, pneumonia, cerebral infarction, acute kidney injury, and heart failure were the common attributing diagnoses on admission. These may reflect the geriatric populations with multiple comorbidities as the mainstay of hospital resources. One nationwide descriptive study in Korea with pediatric visits announced that $15.5 \%$ of patients were admitted to the ED and fever was the most common symptom [12]. However, they did not provide information on the detailed diagnosis or classification for admission. 
We additionally found a common mortality rate and cause of death among admitted patients through the ED. One of the benefits of the NEDIS registry is that death information is included and can be used to calculate nationwide ED mortality. Even though mortality could be impacted by varying illness severity and study population, the rate was quite similar to a previous nationwide study in England (4.8\%) [20]. Another retrospective multicenter cohort study showed that the mortality of acutely admitted patients increased up to 10-fold compared with the general population [21]. Our results showed that pneumonia was the most common cause of death in both the ICU and GW. Furthermore, cardiovascular accidents were common in the ICU, and cancer-related problems were frequent reasons for mortality in the GW. For example, patients with pneumonia tend to require more medical resources than other diseases, such as high flow nasal cannula, mechanical ventilator, and negative pressure rooms [22]. Moreover, patients with pneumonia could negatively impact ED overcrowding, which worsened patients' overall outcomes [22]. Regarding acute ischemic or hemorrhagic stroke, urgent interventions, such as administration of the thrombolytic agent, or hemispheric decompression, with emergent admission through ED to ICU, are known to be the single most important treatment to improve neurologic outcome [23]. Meanwhile, Majzoub et al. reported that early palliative care consultations after ED admission were associated with lower risk for hospital death, and limited palliative care resources needed to be directed to those patients who were admitted through ED [24]. These data could give additional insights for preparation of future administration.

This study has several limitations. First, the NEDIS data were collected from large EDs, therefore, the generalization of the results to small hospitals may not be appropriate. However, the significance of the outcomes could provide detailed information on medical resources. Second, the NEDIS database does not disclose each ED's clinical data, so appropriate patient management could not be confirmed. Third, we used the first NEDIS diagnosis only for both admission and death analyses. While this approach may have deprived analysis of the complete information, we assumed the initial diagnosis would reflect the full situation.

\section{Conclusions}

In conclusion, ED admissions are increasing. Healthcare providers need to understand the epidemiology of ED admissions and prepare to manage these patients with a specific common diagnosis.

Author Contributions: Conceptualization, W.Y.K.; methodology, W.Y.K. and D.W.S.; validation, Y.-J.K. and S.I.H.; formal analysis, J.-s.K.; investigation, J.-s.K.; data curation, H.K., S.J.K., K.S.H., S.M. and S.W.L.; writing—original draft preparation, J.-s.K.; writing—review and editing, W.Y.K., Y.-J.K. and S.I.H.; visualization, J.-s.K.; supervision, W.Y.K.; funding acquisition, W.Y.K. All authors have read and agreed to the published version of the manuscript.

Funding: This research was funded by the special committee in the Korean Society of Emergency Medicine.

Institutional Review Board Statement: Ethical review and approval were waived for this study, due to the retrospective design and anonymous characteristic data of the National Emergency Department Information System.

Informed Consent Statement: Patient consent was waived due to the observational and noninterventional characteristics of the study.

Data Availability Statement: The data presented in this study are available on request from the corresponding author.

Acknowledgments: The authors thank those personnel of the NEDIS participating institutions who contributed the collection and distribution of national data on emergency department utilization.

Conflicts of Interest: W.Y.K., H.K., S.J.K., K.S.H. and S.M. are members of the special committee in the Korean Society of Emergency Medicine for evaluation of emergency medical institutions, but they made no influence on this work. Other authors have no potential conflicts of interest to disclose. 


\section{References}

1. Borgia, F.; Goodman, S.G.; Halvorsen, S.; Cantor, W.J.; Piscione, F.; Le May, M.R.; Fernandez-Aviles, F.; Sanchez, P.L.; Dimopoulos, K.; Scheller, B.; et al. Early routine percutaneous coronary intervention after fibrinolysis vs. standard therapy in ST-segment elevation myocardial infarction: A meta-analysis. Eur. Heart J. 2010, 31, 2156-2169. [CrossRef]

2. Powers, W.J.; Rabinstein, A.A.; Ackerson, T.; Adeoye, O.M.; Bambakidis, N.C.; Becker, K.; Biller, J.; Brown, M.; Demaerschalk, B.M.; Demaerschalk, B.M.; et al. Guidelines for the early management of patients with acute ischemic stroke: 2019 update to the 2018 guidelines for the early management of acute ischemic stroke: A guideline for healthcare professionals from the American Heart Association/American Stroke Association. Stroke 2019, 50, e344-e418. [CrossRef] [PubMed]

3. Demetriades, D.; Karaiskakis, M.; Velmahos, G.; Alo, K.; Newton, E.; Murray, J.; Asensio, J.; Belzberg, H.; Berne, T.; Shoemaker, W. Effect on outcome of early intensive management of geriatric trauma patients. Br. J. Surg. 2002, 89, 1319-1322. [CrossRef] [PubMed]

4. $\quad$ Owens, P.L.; Barrett, M.L.; Gibson, T.B.; Andrews, R.M.; Weinick, R.M.; Mutter, R.L. Emergency department care in the United States: A profile of national data sources. Ann. Emerg. Med. 2010, 56, 150-165. [CrossRef]

5. Habib, M.I.; Khan, K.M.A. Profile and outcomes of critically ill children in a lower middle-income country. Emerg. Med. J. 2017, 35, 52-55. [CrossRef]

6. Schuur, J.D.; Venkatesh, A.K. The growing role of emergency departments in hospital admissions. N. Engl. J. Med. 2012, 367, 391-393. [CrossRef] [PubMed]

7. Morganti, K.G.; Bauhoff, S.; Blanchard, J.C.; Abir, M.; Iyer, N.; Smith, A.; Vesely, J.V.; Okeke, E.N.; Kellermann, A.L. The evolving role of emergency departments in the United States. Rand Health Q. 2013, 3, 3-5. [PubMed]

8. Greenwald, P.W.; Estevez, R.M.; Clark, S.; Stern, M.E.; Rosen, T.; Flomenbaum, N. The ED as the primary source of hospital admission for older (but not younger) adults. Am. J. Emerg. Med. 2016, 34, 943-947. [CrossRef] [PubMed]

9. Tang, N.; Stein, J.; Hsia, R.Y.; Maselli, J.H.; Gonzales, R. Trends and characteristics of US emergency department visits, 1997-2007. JAMA 2010, 304, 664-670. [CrossRef]

10. Yap, X.H.; Ng, C.J.; Hsu, K.H.; Chien, C.Y.; Leonard Goh, Z.N.; Li, C.H.; Weng, Y.M.; Hsieh, M.S.; Chen, H.Y.; Seak, J.C.; et al. Predicting need for intensive care unit admission in adult emphysematous pyelonephritis patients at emergency departments: Comparison of five scoring systems. Sci Rep. 2019, 9, 16618. [CrossRef] [PubMed]

11. Peyrony, O.; Chevret, S.; Meert, A.P.; Perez, P.; Kouatchet, A.; Pene, F.; Mokart, D.; Lemiale, V.; Demoule, A.; Nyunga, M.; et al. Direct admission to the intensive care unit from the emergency department and mortality in critically ill hematology patients. Ann. Intensive Care 2019, 9, 110-119. [CrossRef]

12. Kwak, Y.H.; Kim, D.K.; Jang, H.Y. Utilization of emergency department by children in Korea. J. Korean Med. Sci. 2012, 27, 1222-1227. [CrossRef]

13. Chen, S.X.; Chen, S.X.; Fan, K.; Fan, K.; Leung, L.P.; Leung, L.P. Epidemiological characteristics and disease spectrum of emergency patients in two cities in China: Hong Kong and Shenzhen. World J. Emerg. Med. 2020, 11, 48-56. [CrossRef]

14. Yang, H.J.; Kim, G.W.; Kim, H.; Cho, J.S.; Rho, T.H.; Yoon, H.D.; Lee, M.J. Epidemiology and outcomes in out-of-hospital cardiac arrest: A report from the NEDIS-based cardiac arrest registry in Korea. J. Korean Med. Sci. 2015, 30, 95-99. [CrossRef] [PubMed]

15. Kwon, H.; Kim, Y.J.; Jo, Y.H.; Lee, J.H.; Kim, J.; Hwang, J.E.; Jeong, J.; Choi, Y.J. The Korean Triage and Acuity Scale: Associations with admission, disposition, mortality and length of stay in the emergency department. Int. J. Qual. Health Care 2018, 31, 449-455. [CrossRef] [PubMed]

16. Park, J.B.; Lee, J.; Kim, Y.J.; Lee, J.H.; Lim, T.H. Reliability of Korean Triage and Acuity Scale: Interrater agreement between two experienced nurses by real-time triage and analysis of influencing factors to disagreement of triage levels. J. Korean Med. Sci. 2019, 34, e189. [CrossRef]

17. Carr, B.G.; Kaye, A.J.; Wiebe, D.J.; Gracias, V.H.; Schwab, C.W.; Reilly, P.M. Emergency department length of stay: A major risk factor for pneumonia in intubated blunt trauma patients. J. Trauma 2007, 63, 9-12. [CrossRef] [PubMed]

18. Lee, Y.S.; Lee, Y.R.; Chae, Y.; Park, S.Y.; Oh, I.H.; Jang, B.H. Translation of Korean medicine use to ICD-codes using National Health Insurance Service-national sample cohort. Evid. Based Complement. Altern. Med. 2016, 2016, 1-10. [CrossRef] [PubMed]

19. Vashi, A.A.; Urech, T.; Carr, B.; Greene, L.; Warsavage Jr, T.; Hsia, R.; Asche, S.M. Identification of emergency care-sensitive conditions and characteristics of emergency department utilization. JAMA Netw. Open 2019, 2, e198642-15. [CrossRef]

20. Walker, A.S.; Mason, A.; Quan, T.P.; Fawcett, N.J.; Llewelyn, M.; Stoesser, N.; Finney, J.; Davies, J.; Wyllie, D.H.; Crook, D.W.; et al. Mortality risks associated with emergency admissions during weekends and public holidays: An analysis of electronic health records. Lancet 2017, 390, 62-72. [CrossRef]

21. Flojstrup, M.; Henriksen, D.P.; Brabrand, M. An acute hospital admission greatly increases one year mortality-Getting sick and ending up in hospital is bad for you: A multicentre retrospective cohort study. Eur. J. Intern. Med. 2017, 45, 5-7. [CrossRef]

22. Koller, M.; Nathwani, D.; Merchant, S.; Gast, C.; Quintana, A.; Ketter, N. Medical resource utilization among patients with ventilator-associated pneumonia: Pooled analysis of randomized studies of doripenem versus comparators. Crit. Care 2015, 14, R84. [CrossRef] [PubMed]

23. Meyfroidt, G.; Bollaert, P.-E.; Marik, P.E. Acute ischemic stroke in the ICU: To admit or not to admit? Intensive Care Med. 2014, 40, 749-751. [CrossRef] [PubMed]

24. Majzoub, I.E.; Qdaisat, A.; Chaftari, P.S.; Yeung, S.J.; Sawaya, R.D.; Jizzini, M.; Cruz Carreras, M.T.; Abunafeesa, H.; Elsayem, A.F. Association of emergency department admission and early inpatient palliative care consultation with hospital mortality in a comprehensive care center. Support. Care Cancer 2019, 27, 2649-2655. [CrossRef] [PubMed] 